\title{
Dynamic Simulation of Shipborne Vertical Launching System Under High Wave Level
}

\author{
Yanpeng Dong ${ }^{1, \mathrm{a}}$, Maohua $\mathrm{Qu}{ }^{1, \mathrm{~b}}$, Chengqian $\mathrm{Su}^{1, \mathrm{c}, *}$, Binfei $\mathrm{Qi}^{2, \mathrm{~d}}$, Chen $\mathrm{Yu}^{2, \mathrm{e}}$, Chang $\mathrm{Qi}^{2, \mathrm{f}}$, and \\ Xueming Peng ${ }^{1, g}$ \\ ${ }^{1}$ Beijing Mechanical Equipment Institute, Beijing, 100854, China \\ ${ }^{2}$ Schhool of Automotive Engineering, Dalian University of Technology, Dalian, 116024, China \\ adongyanpengcn@sina.com, bqumaohua_buaa@sina.com, 'suchengqian@126.com, dimqibf@163.com, \\ echeny@mail.dlut.edu.cn, ${ }^{\mathrm{f}}$ qichang@dlut.edu.cn, pengxm298@163.com \\ *Corresponding author
}

Keywords: shipborne vertical launching system; high wave level; launching dynamics

\begin{abstract}
The shipborne vertical launching system originated from the ballistic missile launch system. It is mainly used on ships and submarines for air defense and anti-missile attack and defense against surface ships. The purpose of this work is to study the influence of ship motion on the attitude parameters of the missiles exiting the silo under high wave level to meet the missile launch requirements. The dynamic models of the warship and its vertical launching system were established based on finite element method. The kinematic parameters of the missile were obtained considering the swing motion of the ship. The results can provide guidelines for the design of the shipborne vertical launching system with improved performances.
\end{abstract}

\section{Introduction}

The shipborne vertical launching system is currently a widely used missile launching system by the navy. It has significant features such as large bomb load capacity, high emissivity, all-round attack and multiple-type of bomb shared launch ${ }^{[1]}$. For the vertical launching system, the key parameters include the missile's exit time, exit velocity, exit angle and angular velocity, etc., which are heavily influenced by the ship motion and the missile launch mode. Under the condition of high wave level, the state of the ship at the time of missile launching, including the roll, the pitch and the heave of the ship during the launching process are particularly influential for the missile exit parameters ${ }^{[2]}$. Therefore, it is necessary to study the influence of ship motion on the missile exit parameters under high wave level.

In this work, the finite element (FE) models of the ship and its vertical launching system were first established. Using the ship FE model, we obtained the swing motion parameters of the ship under level-six wave level and took them as boundary conditions for the launching process simulation. Then, we numerically obtained the kinematic parameters of the vertical launching system module by using the system's FE model. LS-DYNA was used for all the simulations. Due to the large number of simulation cases, we developed a MATLAB program for batch processing of input file preparation, simulation submission and post-processing of simulation results.

\section{Dynamic Models}

\subsection{Ship Model}

The ship’s swing motion is assumed as a six degrees of freedom (DOF) rigid body motion under the waves. The motion of each DOF is simplified as a simple harmonic motion, as shown in formula (1). The amplitude, period and phase of each DOF motion can be calculated according to the specific sea level, the ship type, speed and the wave direction ${ }^{[3]}$. The ship's swing motion model is a three DOF rigid body kinematics model as shown in Figure 1, including the roll, the pitch, and the heave ${ }^{[4]}$. 


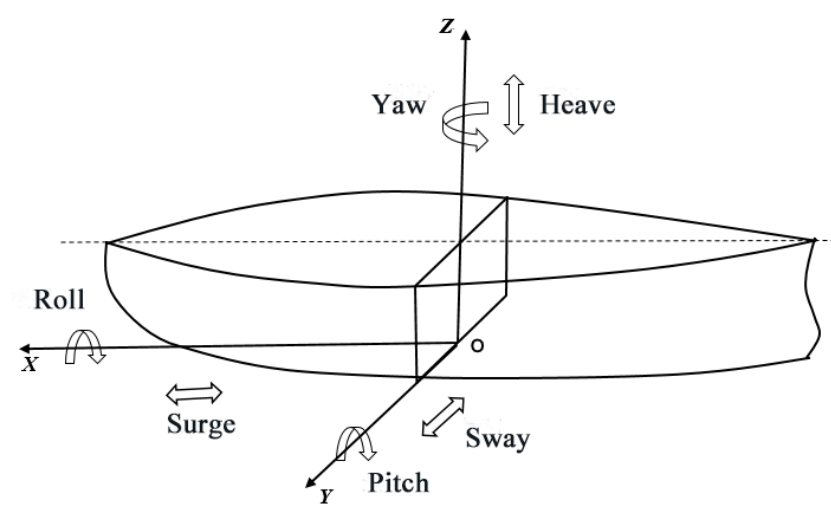

Figure 1 Coordinate system of ship swing motion.

$$
\left\{\begin{array}{l}
X=X_{0} \sin \left(\frac{2 \pi}{T_{X}} t+t_{X}\right) \\
Y=Y_{0} \sin \left(\frac{2 \pi}{T_{Y}} t+t_{Y}\right) \\
Z=Z_{0} \sin \left(\frac{2 \pi}{T_{Z}} t+t_{Z}\right) \\
\theta_{X}=\theta_{X 0} \sin \left(\frac{2 \pi}{T_{\theta X}} t+t_{\theta X}\right) \\
\theta_{Y}=\theta_{Y 0} \sin \left(\frac{2 \pi}{T_{\theta Y}} t+t_{\theta Y}\right) \\
\theta_{Z}=\theta_{Z 0} \sin \left(\frac{2 \pi}{T_{\theta Z}} t+t_{\theta Z}\right)
\end{array}\right\}
$$

In formula (1), $X, Y$, and $Z$ represent respectively the surge, the sway, and the heave, and $\theta_{X}, \theta_{Y}$, and $\theta_{Z}$ represent the roll, the pitch, and the yaw respectively, as shown in Figure $1^{[5]}$. The surge, the sway and the yaw motions were assumed not significant in affecting the performance of the launcher. Therefore, in this work, only three DOF were considered including the roll, the pitch and the heave. The ship's motion time history curves under the condition of 120s level-six wave level were calculated as shown in Figure 2 and Figure 3.

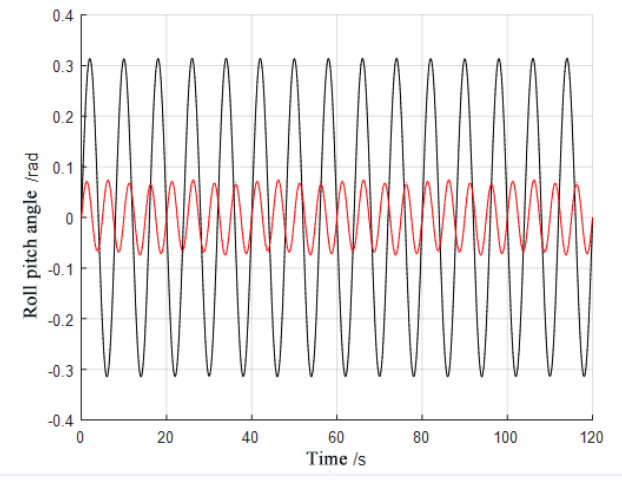

Figure 2 Roll and pitch motion time history.

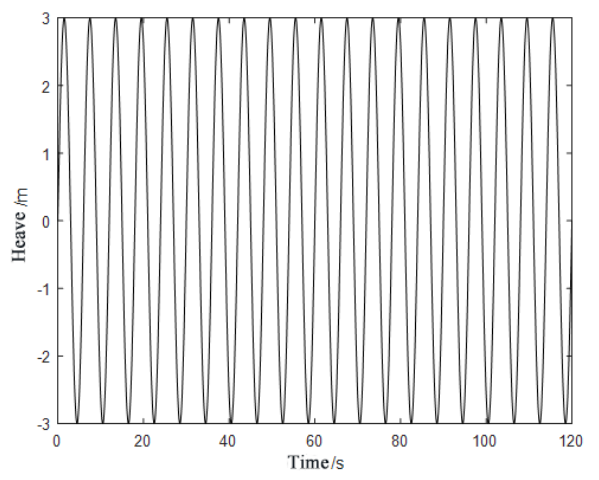

Figure 3 Heave motion time history.

In the actual high wave level, the ship's motion is slightly affected by the ship's speed, size and the wave direction. Therefore, the influences of these factors on the missile's exit parameters can be ignored $^{[6]}$. 


\subsection{Missile Launcher Model}

Under high wave level, the motion of the ship is assumed as rigid body motion, mainly considering the roll, the pitch and the heave of the ship around its swing centre. In the missile launcher dynamic model, we simplified the launching barrel as a rigid body moving along with the ship. During the swing motion, the ejection force drives the missile to launch. Based on this, the FE model was established. The model includes the launch barrel, the missile and the bracket, etc., as shown in Figure 4.

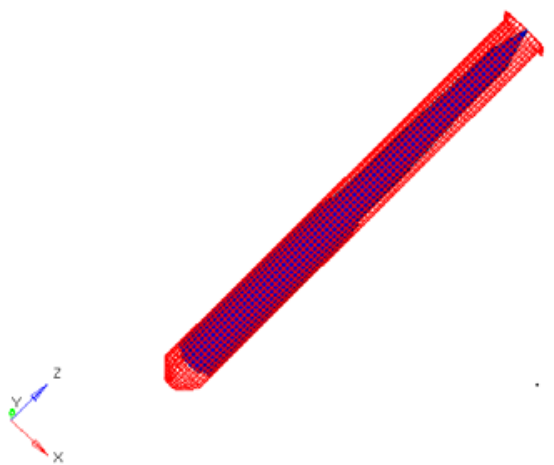

Figure 4 Dynamic model of missile launcher.

Since the bottom center point of the missile launcher model has the same spatial motion with the ship, the rotation angles are the same and the translational displacement is different. The displacement response of the bottom center point $A$ of the missile launcher model with the ship's motion can be expressed as:

$$
\begin{gathered}
r_{O A}^{\prime}=T_{m} * r_{O A}+Z \\
{\left[d_{X}, d_{Y}, d_{Z}\right]^{T}=r_{O A}^{\prime}-r_{O A}}
\end{gathered}
$$

In formula (2):

$$
\begin{gathered}
T_{m}=\left[\begin{array}{ccc}
\cos \theta_{X} & \sin \theta_{X} & 0 \\
-\cos \theta_{Y} \sin \theta_{X} & \cos \theta_{Y} \sin \theta_{X} & \sin \theta_{Y} \\
\sin \theta_{Y} \sin \theta_{X} & -\sin \theta_{Y} \sin \theta_{X} & \cos \theta_{Y}
\end{array}\right] \\
Z=\left[\begin{array}{lll}
0 & 0 & Z
\end{array}\right]^{T}
\end{gathered}
$$

where $T_{m}$ is the rotation transformation matrix (considering the coordinate transformation caused by the roll and the pitch), and $Z$ is the translation transformation vector (considering coordinate transformation caused by the heave). $r_{O A}$ is the coordinate vector of the bottom center point $A$ of the missile launcher model relative to the ship's swing point $O ; d_{X}, d_{Y}$, and $d_{Z}$ indicate the displacement responses of the bottom center point $A$ of the missile launcher model in the $X, Y$, and $Z$ directions, respectively. Here, the coordinate vector $r_{O A}$ of the bottom center point $A$ of the launch module relative to the ship's swing center is $[50.22 \mathrm{~m} 5.93 \mathrm{~m}-1.995 \mathrm{~m}]^{T}$ and the corresponding displacement curve of the bottom center point $A$ of the launch module within 120 s is calculated.

\section{Results and Discussion}

\subsection{Working Condition Statistics}

We analysed the influence of ship's swing motion on the missile's exit parameters under high wave level. Two working conditions were simulated. We performed the dynamics simulations 
under the combined working conditions, the number of working conditions is shown in Table 1:

Table 1 Working condition statistics

\begin{tabular}{|c|c|c|}
\hline $\begin{array}{c}\text { Serial } \\
\text { number }\end{array}$ & Case code & Working condition description \\
\hline 1 & Case_1 & Analysis of single degree of freedom rotation change \\
\hline 1.1 & Case_1.1 & Swing condition $\theta\left(-18^{\circ} \sim+18^{\circ} \sim-18^{\circ}\right), d \theta=9^{\circ}$ \\
\hline 2 & Case_2 & Analyse translational motion changes \\
\hline 2.1 & Case_2.1 & Swing condition $\theta\left(-18^{\circ} \sim+18^{\circ}\right) ; A z\left(-8 \sim+8 \mathrm{~m} / \mathrm{s}^{2}\right)$ \\
\hline
\end{tabular}

For the convenience of analysis, we only considered the influence of the roll angle and the angular velocity on the exit parameters. We analysed the combination of the vertical direction translation and the single DOF rotation and the effect of translational acceleration on the exit parameters.

\subsection{Influence of Rolling Motion}

According to Case1.1 in Table 1 , the swing angle ranges from $-18^{\circ}$ to $18^{\circ}$, and the angular velocity is obtained by angle differentiation. In a swing cycle, the variations of the missile's exit parameters is shown in table 2. For convenience, the maximum value of one of the typical working conditions is listed in the table. The values of other working conditions are normalized according to the above working conditions.

Table 2 Influence of yaw angle on the exit parameters

\begin{tabular}{|c|c|c|c|c|}
\hline $\begin{array}{c}\text { Pendulum } \\
\text { angle } /\left(^{\circ}\right)\end{array}$ & Exit time/(ms) & $\begin{array}{c}\text { Exit } \\
\text { velocity } /(\mathrm{m} / \mathrm{s})\end{array}$ & Exit angle/ $\left({ }^{\circ}\right)$ & $\begin{array}{c}\text { Exit angular } \\
\text { velocity } /(\% / \mathrm{s})\end{array}$ \\
\hline-18 & 452 & 31.5 & 25 & 18 \\
\hline-9 & 0.98 & 0.97 & 0.91 & 0.99 \\
\hline 0 & 0.97 & 0.95 & 0.76 & 1.0 \\
\hline+9 & 0.95 & 0.95 & 0.65 & 0.92 \\
\hline+18 & 0.92 & 0.98 & 0.53 & 0.85 \\
\hline
\end{tabular}

\subsection{Influence of Translational Motion}

Taking case_1.1 condition as the baseline, we further analysed the influence of $\mathrm{Z}$ direction acceleration on the exit parameters. The Z-direction translational acceleration was superimposed, and the working conditions are set as in case_2.1 in the table 1 . The acceleration interval in the Zdirection is taken as $4 \mathrm{~m} / \mathrm{s}^{2}$ in the simulation.

Table 3 Swing condition exit parameters (considering Z-direction acceleration change)

\begin{tabular}{|c|c|c|c|c|}
\hline acceleration $/\left(\mathrm{m} / \mathrm{s}^{2}\right)$ & Exit time $/(\mathrm{ms})$ & $\begin{array}{c}\text { Exit } \\
\text { velocity } /(\mathrm{m} / \mathrm{s})\end{array}$ & Exit angle/ $\left({ }^{\circ}\right)$ & $\begin{array}{c}\text { Exit angular } \\
\text { velocity } /(\% / \mathrm{s})\end{array}$ \\
\hline-8 & 475 & 27.8 & 25 & 23 \\
\hline-4 & 0.95 & 1.01 & 1 & 0.95 \\
\hline 0 & 0.91 & 1.03 & 1 & 0.97 \\
\hline+4 & 0.85 & 1.05 & 1 & 0.96 \\
\hline+8 & 0.80 & 1.02 & 1 & 0.98 \\
\hline
\end{tabular}

The results in table 3 show that the influences of vertical acceleration $A z$ on the exit velocity, the exit angle and the exit angular velocity are very small. Compared with the swing angle and the angular velocity, the influence of $A z$ is negligible. However, the influence of $A z$ on the exit time is greater than that of the swing angle and the angular velocity. The reason is that the launch direction is basically the same as the $Z$ direction. During the launch process, $A z$ affects the acceleration of the launcher tube and greatly affects the acceleration of the missile, and thus affects the exit time. 


\section{Conclusions}

In this work, the ship motion and its influence on the performance of the shipborne vertical launching system under level-six wave level was analysed numerically. The influence of ship swing motion on the missile exit parameters were obtained under typical working conditions.

Simulation results show that the roll angle has a significant influence on the missile exit parameters. In order to ensure that the missile exit parameters are within the safe range, the missile should be launched when the ship is in the equilibrium position. The vertical acceleration $A_{z}$ of the ship has greater influence on the exit velocity and the exit time of the missile than the swing angle of the ship. In the considered range of $A_{z}$, the exit time variation is about $\pm 20 \mathrm{~ms}$, which is about $\pm 5 \%$ of the total exit time, thus can be neglected in reality.

\section{Acknowledgements}

This work is supported by the Defense Industrial Technology Development (Grant No. JCKY2016204C007).

\section{References}

[1] Kulesz, J.J. (1985) MK 41 vertical launching system fleet application. Naval Engineers Journal, 97, $174-184$.

[2] Cook, R., Milla, R., Atkinson, D.C., Revill, N. and Wilson, P. (2010) Development of the Shipborne Rolling Vertical Landing (SRVL) Manoeuvre for the F-35B Aircraft. International Powered Lift Conference.

[3] Ahn, K.Y. (2004) A modeling of impact dynamics and its application to impact force prediction. Proceedings of ACMD, 448 - 453.

[4] Yao, C.R. (1998) The Design of Launcher for Rocket and Missile. Beijing, Beijing Institute of Technology Press.

[5] Timothy, J.M. (2004) Wind turbine ADAMS model linearization including rotational and aerodynamic effects. AIAA Journal, 1370, 1-10.

[6] Yao, C.R., Tang, G.L. and Song, T.L. (1996) The Launch Dynamics of Rocket and Missile. Beijing, Beijing Institute of Technology Press. 